\title{
Macroeconomic Announcement Effects on the Covariance Structure of Bond Returns
}

\author{
Charlotte Christiansen ${ }^{1}$ \\ Department of Finance \\ The Aarhus School of Business \\ Fuglesangs Alle 4 \\ 8210 Aarhus V \\ Denmark \\ Fax: +4586151943 \\ Phone: +45 89486691 \\ E-mail: cha@hha.dk \\ URL: www.hha.dk/ ${ }^{\sim}$ cha/ \\ First Version: February, 1999 \\ This Version: September 1, 1999
}

\footnotetext{
${ }^{1}$ Helpful comments and suggestions from Allan B. Andersen, Tom Engsted, Svend Jakobsen, Jesper Lund, Raman Uppal, and seminar participants at the CEPR Capital Markets Conference, the French Finance Association's 1999 meeting, and the European Finance Association 1999 Doctoral Tutorial are appreciated. Comments and suggestions are sincerely welcomed. The author is responsible for any errors.
} 


\begin{abstract}
This paper contains a multivariate analysis of the effects of macroeconomic news on the U.S. bond market. In particular, we consider releases of Employment Situation and Producer Price Index (PPI) reports (released monthly on pre-announced dates) and the excess returns of $2,3,5,7,10$, and 30 year Treasury bonds using daily data from 1983 to 1998 .

We extend the work of Jones, Lamont and Lumsdaine (1998) who analyze macroeconomic announcement effects on bond returns in a univariate GARCH framework. Our main interest is the impact of macroeconomic news on the conditional variances, covariances, and correlations of bond returns. To this end, we apply the factor-ARCH model of Engle, Ng and Rothschild (1990) using the principal components as substitutes for the real common factors. One factor is shown to be adequate, accordingly, the first principal component is assumed to evolve according to a $\operatorname{GARCH}(1,1)$ model extended to account for differences between announcement and non-announcement days. In this way, we document that the conditional variance of the common factor is deterministically larger on announcement days by 164\%. Moreover, announcement shocks are found to be merely transitory and do not tend to persist. Hence, macroeconomic news cannot explain the observed high degree of persistence of the bond market. Moreover, we do not find any leverage effects of announcement shocks.

The conditional variances of bond excess returns are significantly larger on announcement days and increase with maturity. Likewise, the conditional covariances are larger on announcement days and increase with the maturity of either bond. Finally, the conditional correlations are found to be larger on announcement days, i.e. the co-movement of bond excess returns is stronger on announcement days than on other days.
\end{abstract}

Keywords: Covariance, Macroeconomic News, Multivariate ARCH, Factor Model JEL Classification: G12, C32 


\section{Introduction}

The subject of this paper is to measure the impact of macroeconomic news releases on the U.S. government bond market. In particular, we study the effects that releases of the Employment Situation and the PPI (Producer Price Index) reports, published by the Bureau of Labor Statistics, have on the conditional variances and covariances of excess bond returns using daily data for six different maturities.

Previous research has established that there is a strong relation between releases of employment and PPI figures and the government bond market, cf., e.g., Balduzzi, Elton and Green (1997). These macroeconomic announcements are released periodically (monthly) on pre-announced dates. Hence, they are neither clustered in time nor serially correlated. Furthermore, the contents of the reports are instantaneously available to all market participants. Contrary to stocks and corporate bonds, there is hardly any asset-specific or private information regarding Treasury bonds. Instead, government bond prices and returns depend on macroeconomic variables such as the real interest rate. Accordingly, macroeconomic news affects the bond market. It is well known that the return volatility of financial assets, including bonds, are autocorrelated and highly persistent over time, for a review cf. Bollerslev, Chou and Kroner (1992)). Hence, it has been suggested that the announcements of macroeconomic news could explain the observed high degree of volatility persistence on the bond market. A number of studies have investigated this hypothesis using various univariate frameworks, e.g. Jones et al. (1998), Li and Engle (1998), Balduzzi et al. (1997), and Ederington and Lee (1993). To the author's knowledge, so far no methodical studies have examined the effects of macroeconomic announcements in a multivariate setting, which is the main innovation of this paper.

By applying a multivariate model of bond excess returns, we document that the conditional variances, covariances, and correlations of bond excess returns are significantly larger on macroeconomic announcement days. Moreover, we find that the announcement shocks do not cause the high persistence of shocks observed in the bond market. In fact, the persistence is smaller on announcement days than on other days. Similar results regarding the conditional volatility have been obtained in the univariate study by Jones et al. (1998). In addition, we find that positive and negative announcement shocks have statistically identical persistence which is interesting because it is different from earlier 
work.

This paper represents an improvement of the univariate analysis of responses to risk (i.e. releases of macroeconomic news) which, according to Jones et al. (1998, p. 335), is a potential limitation of the existing literature. Applying a multivariate model to analyze the responses of returns to macroeconomic announcements allows us to draw more general conclusions than univariate analysis. The bond excess returns studied in this paper are strongly correlated and the correlation is even stronger on announcement days. Only a multivariate model will potentially be able to explain why correlations of bond excess returns are stronger on announcement days. Moreover, macroeconomic announcements might offer an explanation of the strong correlation of bond excess returns on all days. In many fields of finance, is it paramount to apply a multivariate model of the distribution of asset returns. These areas include risk management, asset allocation, and asset pricing.

Below is a brief and by no means exhaustive survey of previous literature on the impact of macroeconomic news releases on the bond market. Jones et al. (1998) study the effects of announcements of employment and PPI figures on the conditional volatility of the excess returns of three different U.S. government bonds using daily data. The conditional volatility is assumed to evolve according to a univariate GARCH process which is extended to include level as well as persistence differences on announcement and non-announcement days. The results show that announcement shocks are not persistent and that the conditional variance is significantly higher on announcement days.

In a framework similar to Jones et al. (1998), Li and Engle (1998) study the effects of macroeconomic announcements (CPI, PPI, and Employment situation reports) on the volatility of the U.S. Treasury bond futures. Using a univariate ARCH framework, they find that announcement shocks are not persistent, that positive and negative announcement shocks are significantly different, and that persistence is stronger after bad news is released than after good news. Li and Engle (1998) do not discover significant increases in the returns on announcement days (i.e. no risk premium for macroeconomic news). The ARCH volatility forecast is compared to realized and implied volatility (on options) and it is concluded that the model is correctly specified for the Treasury bond futures.

In a series of papers Fleming and Remolona investigate macroeconomic announcement effects on the Treasury market. Fleming and Remolona (1999a) and Fleming and Remolona (1997) apply one year of intra daily data on the 5 year Treasury note. They find that the largest changes in price and trading volume stem from macroeconomic an- 
nouncements, moreover, the most influential announcements are the employment and the PPI reports. The unexpected component of the announcement is of importance for the reaction of the bond market. Immediately after macroeconomic announcements, the bond price changes sharply and the trading volume declines Subsequently, there is a surge in trading activity and a high level of price volatility persists. Using a longer time sample period, Fleming and Remolona (1999b) study the impact on the yield curve of macroeconomic announcements. An affine yield model is calibrated to the yield changes using announcement surprises as GMM instruments which give rise to a humped shaped yield curves.

Balduzzi et al. (1997) investigate the impact of 27 different economic news announcements on the bond market using intra day data. The paper considers the surprise components of macroeconomic announcements where expectations of the variables are taken from surveys of money market managers. For price reactions of the 10 year Treasury note, the most important announcement is the Non-farm Payroll (which is published in the Employment Situation report), and the second most important variable is the PPI figure. Prices are found to react quickly to news releases. The paper shows that trading volume is significantly higher following "important" economic announcements. Volatility is found to be significantly larger on announcement days, though the paper defines volatility in a non-standard way. ${ }^{1}$

Ederington and Lee (1993) explore the impacts of 19 different announcements on the futures markets of Treasury bonds. Announcements of the employment figure and PPI (amongst 7 announcements) cause significant price changes. In addition, the paper concludes that the day-of-the-week effects are caused solely by the timing of macroeconomic news releases and that volatility remains higher for several hours after macroeconomic announcements.

The outline of this paper is as follows. The theoretical framework of the multivariate model of the bond excess returns is set up in section 2. Subsequently, the data are presented in Section 3. Section 4 contains the empirical results. Finally, concluding remarks are found in Section 5.

\footnotetext{
${ }^{1}$ The volatility is defined as the mean absolute value of the price changes on announcement days during the interval from 0 to 5 minutes after the announcement, over the mean absolute value of price changes of non-announcement days during the same time interval.
} 


\section{The Multivariate Model}

The multivariate model of asset returns that is considered in this paper is an extended version of the factor-ARCH model of Engle et al. (1990). The model is generalized to allow for differences between days of macroeconomic announcements and non-announcement days. As it has been pointed out in the introduction, it is conceivable that applying a multivariate model when considering the effects of macroeconomic announcements might be of great importance for drawing conclusions regarding the effects on the second comoments of asset returns.

The basic feature of factor-ARCH models is that a number of common factors are assumed to evolve according to ARCH processes. Classic references of the factor-ARCH literature include Diebold and Nerlove (1989) and Engle et al. (1990). Diebold and Nerlove (1989) describe a model for the exchange rate dynamics which assumes that a common latent factor influences all the exchange rates, and the factor is assumed to evolve according to an ARCH model. Engle et al. (1990) introduce a factor-ARCH model, where the excess returns of financial assets are described by the Arbitrage Pricing Theory of Ross (1976), and the unobservable factors are described by a GARCH-M specification. Recently, Alexander and Chibumba (1996) have proposed a model which assumes that the principal components of the returns on financial assets are described by ARCH models. The multivariate model applied in this paper will combine the factor-ARCH model proposed in Engle et al. (1990) with the approach of Alexander and Chibumba (1996) to develop orthogonal factors, cf. Christiansen (1999).

The reason for proposing a factor-ARCH model to describe the joint distribution of the returns of a number of financial assets, is that it offers a relatively simple way of introducing a multivariate model that comprises conditional heteroskedastic covariances. It is simple in the sense that it involves comparatively few parameters which is particularly advantageous when the number of assets is large. ${ }^{2}$

\footnotetext{
${ }^{2}$ In the empirical application, we consider 6 different assets. The extended 2 factor-GARCH $(1,1)$ model renders a total of 32 parameters whereas a 6 factor $\operatorname{GARCH}(1,1)$ model (which is equivalent to the multivariate BEKK specification) increases the number of parameters to 84 .
} 


\subsection{Conditional Moments}

We consider the return series of $N$ different assets, which in the empirical application are U.S. government bonds across $N$ different maturities.

The excess returns are defined as the one period holding gain over the short term risk free interest rate. Let $R_{t}$ denote the $N \times 1$ vector of excess returns at time $t$, and let $F_{t}$ denote the information available at time $t$. The conditional mean vector and covariance matrix of $R_{t}$ are denoted $\mu_{t}$ and $H_{t}$, respectively . The excess returns are assumed to be described by a conditional multivariate normal distribution, i.e.

$$
R_{t} \mid F_{t-1} \sim \mathrm{N}\left(\mu_{t}, H_{t}\right) .
$$

A given number, $K$, of common factors are assumed to cause the changes in the returns, and hence, a factor model is considered. To identify the model we have to specify whether the impact of macroeconomic announcements are assumed to work through the factor loadings or the factors themselves. Here we introduce the differences between announcement and non-announcement days via the factors and hence, assume constant factor loadings (i.e. time invariant and announcement day invariant), whereby

$$
R_{t}=\mu_{t}+\sum_{k=1}^{K} \beta_{k} f_{k t}+v_{t} .
$$

The $f_{k t}$ s represent the $K$ common factors influencing all the bonds, and the $\beta_{k}$ s are the $N \times 1$ vectors of factor loadings. $f_{k t}$ has the following properties

$$
\begin{array}{r}
\mathrm{E}\left(f_{k t} \mid F_{t-1}\right)=0 \quad \forall \quad k, t, \\
\mathrm{E}\left(f_{k t} f_{j t} \mid F_{t-1}\right)=0 \quad \forall \quad k \neq j, t,
\end{array}
$$

and

$$
\mathrm{E}\left(f_{k t} f_{k t} \mid F_{t-1}\right)=\lambda_{k t} \quad \forall \quad k, t .
$$

Thus, the factors are martingale difference sequences, and they are conditionally heteroskedastic. $v_{t}$ is the vector of idiosyncratic noise described by

$$
v_{t} \sim \mathrm{N}(0, \Omega),
$$

where $\Omega$ is a positive definite diagonal $N \times N$ matrix.

When modeling $\mu_{t}$ we have to ensure that the factors are serially uncorrelated. Furthermore, our main interest lies in how the conditional covariance matrix evolves over 
time. Hence, we make the simplifying assumption that $R_{t}$ evolves according to a vector autoregressive process of order one $(\operatorname{VAR}(1))$ where a level effect for announcement days is included, that is

$$
\mu_{t}=\Phi_{0}+\Phi_{1} R_{t-1}+\delta_{1} I_{t}^{A},
$$

where $I_{t}^{A}$ is an indicator function for announcement days, $\Phi_{0}$, and $\delta_{1}$ are $N \times 1$ vectors, and $\Phi_{1}$ is an $N \times N$ matrix. Equation (7) is in line with the assumptions regarding the conditional means put forward in Jones et al. (1998) who consider an AR(1) process combined with a level effect for announcement days, i.e. $\Phi_{1}$ is assumed to be diagonal. For reasons similar to ours, Kroner and Ng (1998) make the assumption of the conditional mean being a VAR(1) process in a multivariate ARCH framework. In contrast, Engle et al. (1990) assume that the conditional mean vector is equal to the risk free interest rate plus a time varying risk premium of the common factors. ${ }^{3}$

It follows from the above that the conditional covariance matrix can be described by

$$
H_{t}=\sum_{k=1}^{K} \beta_{k} \beta_{k}^{\prime} \lambda_{k t}+\Omega
$$

As the $\lambda_{k t}$ 's are positive scalars and $\Omega$ is a positive definite matrix, $H_{t}$ will also be positive definite as required. Later, we will be more specific on how the conditional variances of the factors, $\lambda_{k t} \mathrm{~s}$, are allowed to differ on announcement and non-announcement days.

\subsection{Estimation Practicalities}

The multivariate model set up in section 2.1 is estimated using a three-stage estimation technique.

In the first step, we estimate the mean equation to obtain the residuals. In order to do so, the conditional means are estimated by the VAR(1) model from (7). The differences between the returns and their conditional mean are termed the VAR-residuals, $y_{t}$,

$$
y_{t} \equiv R_{t}-\mu_{t}
$$

The VAR-residuals are now the basis time series. The use of the residuals as observed data have been applied by Kroner and Ng (1998) in a similar setting.

\footnotetext{
${ }^{3}$ Engle et al. (1990) apply a GARCH-in-Mean specification for the evolution of the factors' conditional variance. We have also estimated the GARCH-M model, however, the mean parameters were found to be statistically insignificant.
} 
Secondly, we construct $K$ portfolios made up of the various bonds. These portfolios are denoted factor representing portfolios, (FRP), because they are constructed such that the return of portfolio number $k$ is only affected by the $k$ th factor. Furthermore, the FRPs are independent. The vector of weights of the bonds for each of the FRPs is denoted $\alpha_{k} .{ }^{4}$ Following Alexander and Chibumba (1996) the portfolios are constructed using principal components analysis (PCA). For each asset the VAR-residuals are normalized. Let $x$ denote the matrix of the normalized VAR-residuals, and let $\hat{\alpha}$ denote the matrix of eigenvectors of $x^{\prime} x$ ordered according to the size of the corresponding eigenvalue. Then the $N$ PCs are given as $x \hat{\alpha}$. The $K$ FRPs are the $K$ first PCs: $x \hat{\alpha_{1}}, . ., x \hat{\alpha_{k}}, . ., x \hat{\alpha_{K}}\left(\hat{\alpha_{k}}\right.$ is the $k$ th column in $\hat{\alpha}$ ). The resulting FRPs are unconditionally uncorrelated by construction. However, it is not certain that the factors are martingale difference sequences (which is a stronger assumption than being serially uncorrelated). The proportion of variation in $x^{\prime} x$ explained by the $k$ th $\mathrm{PC}$ is equal to the corresponding eigenvalue divided by the sum of all the eigenvalues.

Let $P_{k t}$ denote the return of the $k$ th FRP, i.e. $P_{k t} \equiv \alpha_{k}^{\prime} y_{t} \equiv \hat{\alpha}_{k}{ }^{\prime} x_{t}$, and define the random variable $\epsilon_{k t}$ as

$$
P_{k t}=\left(1+\delta_{2 k} I_{t}^{A}\right)^{\frac{1}{2}} \epsilon_{k t}
$$

where $\delta_{2 k}>-1$. The conditional distribution of $\epsilon_{k t}$ is given as follows

$$
\epsilon_{k t} \mid F_{t-1} \sim \mathrm{N}\left(0, \theta_{k t}\right)
$$

where $\theta_{k t} \equiv \lambda_{k t}+\alpha_{k}^{\prime} \Omega \alpha_{k}$. There is a one-to-one correspondence between the FRPs and the common factors and the FRPs also have mean zero and exhibit heteroscedasticity. The conditional variance of the $k$ th FRP is deterministically greater by $\left(1+\delta_{2 k}\right)$ on announcement days. To make the model empirically applicable, we have to introduce certain parametric assumptions on the way the conditional variances of the FRPs, the $\theta_{k t} \mathrm{~s}$, evolve over time. We follow Engle et al. (1990) and make the assumption that the aforementioned portfolios depend solely on their own history. ${ }^{5}$ We further assume that the FRP returns can be described by a $\operatorname{GARCH}(1,1)$ formulation which has been

\footnotetext{
${ }^{4}$ Engle et al. (1990) apply predefined (non-estimated) FRP weights.

${ }^{5}$ If we were to use a general portfolio representation, the estimation would be much more involved because we would assume that the returns of a FRP depend on information of all the FRP returns. Thus, we would need to apply a multivariate ARCH process.
} 
expanded to allow for differences on announcement days, i.e.

$$
\theta_{k t}=\sigma_{k}+\left(\phi_{k}+\delta_{3 k} I_{t-1}^{A}+\delta_{4 k} I_{t-1}^{A} I_{k, t-1}^{-}\right) \epsilon_{k, t-1}^{2}+\left(\varphi_{k}+\delta_{5 k} I_{t-1}^{A}\right) \theta_{k, t-1}
$$

where $\sigma_{k} \equiv \alpha_{k}^{\prime} \Omega \alpha_{k}$ and $I_{k t}^{-}=1$ if $P_{k t}<0$ and 0 else. To ensure that the conditional variance is strictly positive, the following constraints are applied ${ }^{6}$ :

$$
\sigma_{k}>0, \quad \phi_{k}, \phi_{k}+\delta_{3 k}, \phi_{k}+\delta_{3 k}+\delta_{4 k}, \varphi_{k}, \varphi_{k}+\delta_{5 k} \geq 0
$$

In (12), we follow Li and Engle (1998) and allow positive and negative announcement shocks to have different implications on the conditional volatility, i.e. including a leverage effect. The specification in (12) is in fact an extension of the Glosten, Jagannathan and Runkle (1993) GARCH model where we have included announcement effects.

There is no unique way of measuring volatility persistence; however, one simple metric is the sum of the GARCH parameters. The specification in (12) allows for differences in the persistence on announcement and non-announcement days in that the sum of the GARCH parameters is larger on announcement days by $\left(\delta_{3 k}+\delta_{4 k}+\delta_{5 k}\right)$ and $\left(\delta_{3 k}+\delta_{5 k}\right)$ for negative and positive shocks, respectively.

The announcement GARCH model in (10), (11), and (12) is similar to the specification for the conditional variance of the bond excess returns in Jones et al. (1998). Their most general specification of the conditional variance of the bond excess return for a given maturity is a "regime switching" model which corresponds to (10), (11), and (12) expanded by the multiplicative factor $\left(1+c I_{t-1}^{A}\right)^{\frac{1}{2}}$ in (10) (i.e. the conditional variance deterministically changes regime the day following an announcement) and is reduced to being symmetric, i.e. $\delta_{4 k}=0$. For all maturities examined, they find that the conditional variance does not follow the regime switching process. Their results lead us to restrict our analysis to the somewhat simpler GARCH model in (10) and (12). ${ }^{7}$

Thirdly, after estimating the GARCH model of the FRPs we proceed by estimating the model of the VAR-residuals. The conditional joint distribution of the VAR-residuals is given by

$$
y_{t} \mid F_{t-1} \sim \mathrm{N}\left(0, H_{t}\right)
$$

\footnotetext{
${ }^{6}$ Apart from $\sigma_{k}>0$, the restrictions in (13) are not binding in the empirical applications.

${ }^{7}$ In addition, we have estimated the regime switching model of Jones et al. (1998) for the conditional variances of the FRPs. However, we find that the lagged announcement indicator function is not significant for any of the FRPs.
} 
The above model of the FRPs can be utilized to rewrite $H_{t}$ as

$$
H_{t}=\sum_{k=1}^{K} \beta_{k} \beta_{k}^{\prime}\left(\left(1+\delta_{2 k} I_{t}^{A}\right) \theta_{k t}-\sigma_{k}\right)+\Omega=\sum_{k=1}^{K} \beta_{k} \beta_{k}^{\prime}\left(1+\delta_{2 k} I_{t}^{A}\right) \theta_{k t}+\Omega^{\star}
$$

where $\Omega^{\star} \equiv \Omega-\sum_{k=1}^{K} \beta_{k} \beta_{k}^{\prime} \sigma_{k}$. We see that the conditional covariance matrix for the asset returns can be rewritten as a function where the only random variables are the conditional variances of the FRPs. Moreover, the conditional covariance matrix differs on announcement and non-announcement days via the parameters $\delta_{2 k}$. The introduction of the FRPs has simplified the equation of the conditional covariance of the VAR-residuals. The $N(K+1)$ parameters of $H_{t}$ are estimated simultaneously using the conditional variance of the FRPs as input. ${ }^{8}$ Using the simultaneous estimation procedure allows us to test the significance of the FRPs.

\section{The Data}

\subsection{Bond Returns and Announcement Data}

The examined return series are the daily excess returns of $2,3,5,7,10$, and 30 year U.S. Treasury bonds. The excess return is defined as the return of holding the bond in excess of the risk free spot rate, which by assumption is equal to the 3 month Treasury bill rate. Ideally, we would apply an overnight risk free interest rate. Unfortunately, we would then have to use interest rates from the money market, i.e. LIBOR rates, whereby we incur other kinds of problems. As a result, we stick to the 3 month Treasury rate. The data cover the period January 1, 1983 to December 31, 1998, providing a total of 3999 observations. Hence, the analysis covers the period after the so called Monetary Experiment of the U.S. Federal Reserve. From October 1979 to late 1982 the Federal Reserve targeted the quantity of reserves, and in particular the stock of M1 money. In contrast, following the Monetary Experiment, the Federal Reserve returned to targeting the level of interest rates.

\footnotetext{
${ }^{8}$ Engle et al. (1990) apply a somewhat different multi-step estimation procedure, which has been termed the 2SUE (two stage univariate estimation) procedure by Lin (1992). In the first step they estimate the GARCH models for the FRPs (i.e. in this paper we use the same first step). In the second step, Engle et al. (1990) start out by estimating the parameters of the diagonal elements of $H_{t}$ individually (i.e. the conditional variances). Afterwards, the off-diagonal elements of $H_{t}$ (i.e. the conditional covariances) can be calculated. In contrast, we estimate the parameters of $H_{t},\left(\Omega, \beta_{1}, \ldots, \beta_{k}, . . \beta_{K}\right)$, simultaneously.
} 
The returns from holding the bonds are calculated from the Federal Reserve's "daily constant maturity interest rate" series, in the same manner as Jones et al. (1998). The constant maturity yields are interpolated by the U.S. Treasury from the daily yield curve, which is based on the closing bid yields of actively traded Treasury securities in the over the counter market, i.e. the secondary market. The returns (which are calculated using hypothetical bonds with the relevant time to maturity) consist of two parts; capital gain and excess return over the short risk free rate in the holding period. U.S. Treasury bonds have coupon payments semi-annually and the next coupon payment is assumed to take place in 6 months. Furthermore, the coupon on the hypothetical bond is half the stated annual coupon yield. Hence, the price of the bond at the beginning of the holding period is equal to its face value. The prevailing price at the end of the period is calculated as the price of the hypothetical bond discounted by the next day's yield. The capital gain is calculated as the discretely compounded return of holding the bond using the beginning and end of period prices described above. To obtain the total excess return on the bond, we have to add the excess income over the short term risk free interest rate during the holding period. The excess income of the bond is calculated as the difference between the half yearly yield on the bond and the 3 month bond, multiplied by the number of holding days (from one to four) divided by 182.5 days. ${ }^{9}$

The macroeconomic announcements included in the present study are the Employment Situation Report and the PPI Report published by the Bureau of Labor Statistics. There are 188 announcements of Employment Reports and PPI statistics which implies a total of 376 different announcement days. The PPI and the employment reports are released monthly, and always at 8.30 AM EST.

The two types of macroeconomic announcements considered in this paper are chosen for a couple of reasons. Firstly, in a recent study Balduzzi et al. (1997) investigate the impacts of 27 different types of economic announcements on the price changes of Treasury bond prices. Their study shows that the most important types of macroeconomic announcements for changes in e.g. the 10 year bond price are the Employment Situation Report and the PPI Report. Secondly, these types of macroeconomic news are released periodically on pre-announced dates and are thus serially uncorrelated. Finally,

\footnotetext{
${ }^{9}$ The daily excess returns of the 5, 10, and 30 year bonds of the period 1983 to 1995 have been downloaded from Owen Lamont's home page at the University of Chicago. The remaining returns have been downloaded from the home page of the Federal Reserve Bank of Chicago.
} 
the empirical analysis is comparable to Jones et al. (1998). ${ }^{10}$

\subsection{Preliminary Analysis}

Before we turn to the estimation of the factor ARCH model, we take a quick look at the sample moments of the data. Table 1 includes summary statistics for the bond excess returns, i.e. unconditional moments. Apart from considering the full sample, the observations have been grouped into announcement and non-announcement days. ${ }^{11}$

It is evident, that the average excess returns are larger on announcement days for all maturities. The sample mean of the excess returns for the different maturities on announcement days are between $0.021 \%$ and $0.091 \%$ whereas on non-announcement days the averages range between $0.006 \%$ and $0.018 \%$. It is noticeable that for the full sample the corresponding figures are $0.007 \%$ and $0.025 \%$. This indicates that the announcement days cause a large amount of the excess returns. For all the breakdowns of the data, it is the case that the average excess returns increase with time to maturity. To assess the significance of the excess returns being larger on announcement days, we run an Ordinary Least Squares regression for each maturity of the excess return on the announcement indicator function, $I_{t}^{A}$, cf. Table 2. In no cases, do we find statistically significant macroeconomic risk premia. OLS regressions on leading and lagged announcement indicator functions, reveal that there are no macroeconomic risk premie shifted in time either, (not in table). Hence, there is no statistical evidence of differences between announcement days and other days regarding bond excess returns.

Another interesting feature of the data is that there are considerable differences between the sample covariance matrixes (variances and covariances) for announcement and non-announcement days. In fact, the entries in the covariance matrix are 2.1 to 2.9 times larger on announcement days than on non-announcement days. To evaluate the significance of the differences between the level of variances and covariances on announcement days, we use squared excess returns as proxies for variances and multiplied excess re-

\footnotetext{
${ }^{10}$ The study in Jones et al. (1998) is limited to 3 different maturities, (5, 10, and 30 year) and the data cover an earlier time period, (October 1979 to December 1995).

${ }^{11}$ Following Jones et al. (1998), no distinction is made between the employment and PPI announcements and the empirical estimation in Section 4 is also based on this assumption. Furthermore, Li and Engle (1998) find that there are no report specific effects for the conditional volatility on Treasury bond futures.
} 
turns of different bonds as proxies for covariance. Again, we run OLS regressions on the announcement day indicator function, cf. Table 2. In all instances, the coefficients are significantly larger than zeros. This is a sign of level differences of variances and covariances on announcement days. On days following news releases, we do not find any differences between the level of the proxy for the covariance matrix, whereas it is statistically smaller on days prior to releases. However, these differences are small in an economic sense, (tables of the regressions on the announcement indicator function lagged and leaded are not included).

Generally, the correlation coefficients of the excess returns are remarkedly high. For the full sample, the correlation coefficients range between 0.786 and 0.974 . On announcement days, all correlation coefficients are larger than for the full sample, (0.849 to 0.988). The opposite is the case for non-announcement days; 0.727 to 0.971 . This indicates that on days of macroeconomic announcements, the co-movements of bond excess returns are stronger than on non-announcement days.

For illustrative purposes the properties of the daily excess returns of the 3 year and 10 year bonds are shown graphically in Figure 1. The graphs suggest that a model including heteroscedasticity is required to describe the evolution of the bond excess returns as there are signs of volatility clustering.

\section{Empirical Results from the Treasury Bond Market}

This section presents the empirical results of applying the multivariate ARCH model which incorporates announcement effects to the U.S. Treasury market. As mentioned above, the estimation is conducted using a multi-step procedure. This section is organized according to the multi-step procedure. In the first step, the conditional mean equation is estimated and the VAR-residuals are constructed. In the second step, we form the FRPs for which the announcement $\operatorname{GARCH}(1,1)$ model is estimated. Finally, the parameters of the conditional covariance matrix are estimated.

\subsection{Conditional Means}

Recall that the conditional means of the excess returns are assumed to be described by a $\operatorname{VAR}(1)$ process where a level effect for announcement days is added, cf. (7). A VAR(1) 
process is of high enough order to eliminate autocorrelation of the excess returns as well as the returns of the FRPs. The VAR-residuals are constructed as the difference between the excess returns and the conditional mean, cf. (9). The VAR-residuals are then used as the observed data in the remaining analysis. This procedure has also been applied by Kroner and $\mathrm{Ng}$ (1998) in a multivariate ARCH setting.

The VAR-residuals are estimated using OLS. The parameter estimates (and White's standard errors) are given in Table 3. The addition to the conditional mean on announcement days is not significantly different from zero (i.e. applying two sided $t$-tests) at the $10 \%$ level of significance for any of the maturities. One sided tests for the conditional means being larger on announcement days result in p-values in the range of $5.7 \%$ and $12.7 \%$. In contrast, the joint Wald test results in a p-value of $3.6 \%$ (test statistic is 13.5 which is $\chi^{2}(6)$ distributed under the null). Hence, this provides evidence that releases of macroeconomic news are associated with risk premia. ${ }^{12}$ The point estimates of the addition to the conditional means on announcement days ranges between 0.014 and $0.074 \%$ points. We observe that the level effect of macroeconomic announcements on the conditional mean in general is increasing with the time to maturity of the bond. The announcement day level effects of the conditional means are smaller than those found by Jones et al. (1998). The moderated results are due to the more recent time period that we consider. A few of the off-diagonal entries in the parameter matrix, $\Phi_{1}$ are significantly different from zero indicating that the $\operatorname{AR}(1)$ specification in Jones et al. (1998) might not provide an adequate description of the mean equation and it follows that the VAR(1) specification is more appropriate than the $\mathrm{AR}(1)$ assumption.

\subsection{Announcement ARCH Model of Factor Volatility}

In order to construct independent factors, we apply principal components analysis to estimate the FRPs which are used as substitutes for the real common factors of the bond

\footnotetext{
${ }^{12}$ We have estimated an extended version of the mean equation where we allow all the elements of the matrix $\Phi_{1}$ to take on different values on announcement days. Interestingly, at a $5 \%$ level we find that $\Phi_{1}$ is jointly statistically different on announcement days even though merely 2 elements are individually significant. Moreover, the introduction of this additional dependence on $I_{t}^{A}$ causes the $\delta_{1}$ vector to be insignificant (p-value equals 67\%). Apart from the desirability of a simple model, we also want to be able to compare our results with the results of Jones et al. (1998). Thus, we adhere to the simpler version of the mean equation in (7).
} 
market. Table 4 contains the details of the PC analysis. The first principal component explains $92.7 \%$ of the variation in the data, whereas the second and the third principal components explain $4.7 \%$ and $1.1 \%$ of the variation in the data, respectively. This suggests that a two factor model will provide an adequate description of the bond market. Thus, in the subsequent empirical analysis we will initially employ a two factor model. At this point, it is not easily testable how many factors to include, unless we assume that the covariances are time invariant, c.f. Johnson and Wichern (1992, chapter 9). We notice that the first FRP is close to being an equally weighted average of the normalized excess returns of the six bonds, cf. Table 4, Panel B. In practice, this is parallel to Engle et al. (1990) who analyze a one factor model under the assumption that the FRP is an equally weighted portfolio of 11 Treasury bills with different maturities. The second FRP is composed of both long and short positions of the various bonds, having the greatest weight on the extreme maturities.

As required, the returns of the constructed FRPs are not autocorrelated (Ljung-Box statistics for autocorrelation of order 5 have p-values in excess of $50 \%$ ). The squared returns of the FRPs are significantly autocorrelated which provides evidence of ARCH effects.

Our objective is to empirically analyze the nature of the implications of announcements on the FRP conditional variance. The estimation is conducted using Quasi Maximum Likelihood (QML) with a Gaussian likelihood function and applying robust standard errors. $13 \quad 14 \quad 15$

\footnotetext{
${ }^{13}$ For the estimation of the GARCH $(1,1)$ model the standard univariate Gaussian log-likelihood function is applied. For the estimation of the model of the conditional covariance matrix, the log-likelihood function is given as,

$$
L_{T}\left(\Omega, \beta_{1}, \ldots, \beta_{k}, . ., \beta_{K}\right)=T^{-1} \sum_{t=1}^{T}-.5\left(N \ln (2 \pi)+\ln \left(\left|H_{t}\right|\right)+y_{t}^{\prime} H_{t}^{-1} y_{t}\right),
$$

subject to $\Omega$ be positive definite and $H_{t}=\sum_{k=1}^{K} \beta_{k} \beta_{k}^{\prime}\left(\theta_{k t}-\sigma_{k}\right)+\Omega$.

${ }^{14}$ The estimation is conducted in GAUSS using the GAUSS module Constrained Maximum Likelihood. A combination of the Berndt-Hall-Hall-Hausman and the Newton-Raphson maximization algorithm is employed. Starting values for the conditional variance are set to the unconditional variance. The likelihood function is conditional on the first observation.

${ }^{15}$ The QML parameter estimates are consistent, cf. Hamilton (1994, chapter 21). The QML standard errors are calculated as the cross product of the first derivatives of the log-likelihood function, pre- and post-multiplied by the inverse Hessian of the log-likelihood function.
} 
We have estimated a number of other specifications apart from the announcement GARCH $(1,1)$ model in (10) and (12). To conserve space, diagnostic tests are not tabled for these models. In addition, the diagnostic tests are qualitatively identical to those of the general GARCH model. A natural starting point is to examine the properties of the conditional variance when we do not distinguish between announcement and nonannouncement days at all. In so doing, we estimate an ordinary $\operatorname{GARCH}(1,1)$ model, i.e. imposing the restriction that $\delta_{k 2}=\delta_{k 3}=\delta_{k 4}=\delta_{5 k}=0, k=1,2$. The results are shown in Table 5, Panel A. The conditional volatility of $P_{1 t}$ is highly persistent and the sum of the GARCH parameters is 0.978 . The equivalent sum for the conditional volatility of $P_{2 t}$ amounts to 0.969 . As $\phi_{k}+\varphi_{k}<1, P_{1 t}^{2}$ and $P_{2 t}^{2}$ are covariance-stationary.

In the following, we will extend the analysis to account for differences between announcement and non-announcement days. For the moment, we want to test the hypothesis of the conditional variance being greater on announcement days than on other days. To this end we propose a simple $\operatorname{GARCH}(1,1)$ model where we allow the conditional variance of $P_{k t}$ to be deterministically larger on announcement days by $\delta_{k 2}$ but retain the other restrictions of the ordinary GARCH model: $\delta_{k 3}=\delta_{k 4}=\delta_{5 k}=0$. The estimated simple GARCH $(1,1)$ model (reported in Table 5, Panel B) leads to a number of interesting insights. Firstly, the conditional variance of $P_{1 t}\left(P_{2 t}\right)$ is $178 \%$ (67\%) higher on announcement days than on non-announcement days. Apart from being statistically significant, these differences have economic implications that are non-negligible. Secondly, including a difference in the level of the conditional variance on announcement days hardly alters the persistence of the volatility. The sum of the GARCH coefficients is reduced to 0.977 and 0.962 respectively. By way of comparison, Jones et al. (1998) estimate the simple GARCH $(1,1)$ model for the excess returns of three different bonds and find that the conditional variances are between $102 \%$ and $139 \%$ larger on announcement days.

To get a thorough description of the persistence of announcement day shocks the general model defined in (10), (11), and (12) is estimated for the two FRPs. In addition to the level difference of the conditional variance on announcement days, the general GARCH model allows the persistence of announcement shocks to differ from the shocks to the FRP returns on other days. Furthermore, negative announcement shocks are allowed to influence the conditional volatility differently from positive announcement shocks. The estimation results are reported in Table 6 . We notice that $\delta_{k 4}$ and $\delta_{5 k}$ are not significantly different from zero for both portfolios. Furthermore, $\delta_{13}$ is of the same absolute size as 
$\phi_{1}$. The robust Wald statistics of the null hypotheses of $\phi_{k}=-\delta_{3 k} \wedge \delta_{4 k}=\delta_{5 k}=0$ are 0.002 and 0.347 , respectively which are $\chi^{2}(3)$ distributed under the null. As a result we cannot reject the null hypotheses. The persistence of the FRP returns is larger for negative announcement shocks but insignificantly so. ${ }^{16}$ Hence, we re-estimate the reduced $\operatorname{GARCH}(1,1)$ model of $(10),(11)$, and $\theta_{k t}=\sigma_{k}+\phi_{k}\left(1-I_{t-1}^{A}\right) \epsilon_{k, t-1}+\varphi_{k} \theta_{k, t-1}$. We refrain from commenting on the general GARCH model any further.

The empirical results from estimating the reduced GARCH $(1,1)$ model are presented in Table 7. The main insights from this estimation concern the persistence of the conditional volatility. For non-announcement days, the sum of the GARCH parameters are 0.981 and 0.975 respectively. Hence, non-announcement days have larger persistence than the full sample. Announcements dampen the persistence of the conditional volatility, the sum of the GARCH parameters are equal to 0.925 and 0.923 . Thus, we conclude that the conditional variance of the FRPs is larger on announcement days and that the increase is purely transitory. Releases of macroeconomic news do not cause the high degree of persistence observed in the government bond market, in fact the opposite is the case. Furthermore, macroeconomic announcements reduce the spill-over effects of previous shocks to the bond excess returns. This provides evidence that the market incorporates macroeconomic news into the bond prices during the day of release.

If the normality assumption is valid the studentized residuals are standard normal distributed. Both FRPs exhibit leptokurtosis and $P_{2 t}$ is also skewed, cf. Table 7, Panel B. However, since the first two conditional moments are correctly specified inference based on the Gaussian likelihood function is still valid (when combined with robust standard errors). We also notice that there are no signs of ARCH(2) effects. ${ }^{17}$ The applied LM test is also a test for no $\operatorname{GARCH}(1,1)$ effects. Hence, the $\operatorname{GARCH}(1,1)$ model seems to be adequate.

A number of robustness tests of the announcement $\operatorname{GARCH}(1,1)$ model have been conducted. To test for parameter instability we construct an indicator variable that divides the data into two equally sized sub periods. We allow all the four parameters of the reduced GARCH model to be different in the two sub periods, (results from this

\footnotetext{
${ }^{16}$ This is in contrast to the findings of Li and Engle (1998), who document that in the case of Treasury bond futures, negative announcement shocks have greater impact on future conditional volatility than positive shocks.

${ }^{17}$ For the second FRP the test statistic is significant at a $10 \%$ level of significance, i.e. marginally significant.
} 
estimation are not included). For the first FRP, neither of the parameters are individually significantly different in the two sub periods. In contrast, the joint robust Wald test rejects the null hypothesis of all four parameters being identical in both periods. We also conduct a Wald test for the null hypotheses of $\sigma_{1}, \phi_{1}$, and $\varphi_{1}$ being identical in both sub periods, this hypothesis cannot be rejected. Hence, there are certain indications of parameter instability of the GARCH model of FRP one. For the second FRP neither of the parameters are individually significantly different in the two sub periods, which is also supported by an insignificant joint Wald test statistic. Hence, there are no signs of parameter instability for the second FRP. On the basis of the above findings we decide to adhere to the reduced $\operatorname{GARCH}(1,1)$ model for both of the FRPs and carry on with the next step of the estimation procedure. ${ }^{18}$

\subsection{Announcement Model of Conditional Covariance}

We continue by estimating the parameters of the two factor model of the conditional covariance, $H_{t}$, cf. (15). The QML estimates of the parameters are reported in Table 8, Panel A.

In two instances, the elements of $\Omega$ are constrained by the restriction that $\Omega$ be positive definite. ${ }^{19}$ The factor loadings of the first FRP are all significantly positive (at any usual level of significance). We also notice that the factor loadings increase with the maturity of the bond.

In contrast, the factor loadings of the second FRP are in general decreasing with the time to maturity, and 4 are negative. However, at a $5 \%$ level only 1 factor loading is statistically significant. This suggests that we test the hypothesis of all the elements of $\beta_{2}$ being equal to zero simultaneously. The robust Wald test cannot reject this (test statistic of 1.235 which is $\chi^{2}(6)$ distributed under the null). Hence, we conclude that a one factor model is preferred to the two factor model. Diagnostic tests of the studentized residuals, cf. Table 8, Panel B, are qualitatively identical to those of the one factor model and we

\footnotetext{
${ }^{18}$ As mention above, we have also estimated the GARCH(1,1)-M model, where the mean parameter is insignificant for both FRPs. We have also tried out the regime switching model of Jones et al. (1998) and find that the lagged announcement indicator is insignificant for both FRPs. This is probably because the return series are based on closing prices whereas the announcements are released at 8.30 AM. Hence, the time lag is too long for lagged announcements to enter significantly.

${ }^{19}$ Hence, these parameter estimates do not have a standard error connected to them, denoted by (-).
} 
postpone our comments.

Re-estimating the conditional covariance matrix in a one factor setting hardly alters the parameter estimates of the factor loadings, $\beta_{1}$, which further supports the reduction of included FRPs. The factor loadings are significantly positive and increasing with the maturity of the bond and fall in the range of 0.049 to 0.269 . The fact that the factor loadings increase with the maturity goes well with the findings of the summary statistics, cf. Table 1, where we find that the unconditional covariance increases with the maturity of one of the bonds (ceteris paribus).

Diagnostic tests of the studentized residuals reveal that all the bonds are leptokurtotic. The 2 year bond is skewed (and the 10 year bond to a minor degree). The main problem is that the 2 year bond has $\mathrm{ARCH}(2)$ effects remaining. As this is merely the case in one of six cases, we do not extend the number of lags in the GARCH specification. The same remarks as in the previous subsection applies: Inference based on the QML estimation using a Gaussian likelihood function is valid.

We check the specification of the model of the covariance matrix (15) in a number of ways. Firstly, we allow the idiosyncratic shocks, (i.e. the diagonal matrix $\Omega$ ), to be different on announcement and non-announcement days. A simultaneous Wald test documents that $\Omega$ is equivalent on announcement and non-announcement days which is consistent with the model specification. As an additional check of model specification, we estimate the one factor model and allow the factor loadings to be different on announcement and non-announcement days, i.e. the elements of $\beta_{1}$ are larger on announcement days but not by the same amount. A simultaneous Wald test shows that the factor loadings are statistically equivalent on the announcement and non-announcement days. Furthermore, we test for parameter instability in the one factor model using the indicator function from above that divides the sample into two equally sized sub periods. We apply the Wald test and find that $\beta_{1}$ is statistically identical in both sub periods. The above findings provide evidence that the one factor-GARCH $(1,1)$ model suggested in this paper is well-specified.

We conclude that the conditional variance and covariance of the bond excess returns are larger on announcement days, because the conditional variance of the FRP has this characteristic. We cannot state in a simple manner how much larger the conditional covariance is on announcement days. Ignoring $\Omega^{\star}$ in $(15)$, we can conclude that the conditional covariance matrix is also $164 \%$ times larger than the covariance matrix applicable for non-announcement days. 
The estimated model results in a conditional correlation matrix which is greater on announcement days than on non-announcement days. Hence, releases of macroeconomic news amplifies the common movement in the bond market which tightens the correlation of the VAR-residuals. Hence, this feature of the sample statistics is incorporated in the model. The expression of how much larger the conditional correlation is on announcement days is rather long and involved and is not included.

Table 10 contains the sample means, standard deviations, minimum and maximum values for the conditional variances, covariances, and correlation coefficients. Apart from considering the full sample, we calculate these summary statistics for announcement and non-announcement days. We find that the sample means of the conditional variances, covariances, and correlation coefficients are larger on announcement days than on nonannouncement days. Likewise, the sample means of the conditional variances, covariances, and correlation coefficients are smallest on non-announcement days, "medium" sized for the full sample, and largest on announcement days. This is the case for all maturities included in the analysis. The conditional variances, covariances, and correlation coefficients attain their minimum values on non-announcement days and their maximum values on announcement days. The conditional variances and covariances applicable for announcement days are from 100 to $200 \%$ larger than those for applicable for non-announcement days. This goes along very well with the results from above, i.e. that if we ignore $\Omega^{\star}$ the conditional covariance matrix is $164 \%$ times larger on announcement days than on non-announcement days. The order of magnitude of the differences of the average conditional correlation coefficients on announcement and non-announcement days is smaller; they are between 3 and $14 \%$ larger on announcement days than on non-announcement days.

\section{Conclusion}

In this paper we have investigated how variances and covariances of U.S. bonds react to releases of macroeconomic news. Specifically, we have considered the daily excess returns of $2,3,5,7,10$, and 30 year government bonds during the period 1983 to 1998 . The macroeconomic announcements that have been scrutinized are the Employment Situation and the PPI reports published monthly by the Bureau of Labor Statistics.

In the previous literature on the effects of macroeconomic news on the bond market, 
the analysis is conducted using univariate frameworks, cf. e.g. Jones et al. (1998), Li and Engle (1998), Balduzzi et al. (1997), and Ederington and Lee (1993). The main contribution of this paper has been to extend this analysis to a multivariate framework and to this end we have applied a factor-ARCH model.

We have found that the conditional means of excess returns on bonds are larger on announcement days.

The first and the second principal components (denoted FRPs) are used as substitutes for the real underlying factors. The FRPs are assumed to evolve according to extended GARCH(1,1) processes. In this way, we have documented that the conditional variance of the FRPs is larger on announcement days by $164 \%$ and $71 \%$ respectively. The impact of positive and negative announcement shocks appear to be identical. The persistence of the common factors is larger on non-announcement days than on announcement days. Hence, macroeconomic announcements do not provide an explanation of the high degree of persistence of shocks to the bond market. The information of macroeconomic news releases are incorporated into the bond prices very fast.

Subsequently, we have estimated the factor loadings from the conditional covariance matrix. In this way we have found that the second FRP is superfluous. The estimated one-factor model results in significantly positive factor loadings. A number of specification tests have been conducted which support the model.

The main findings of the empirical work are that the conditional variances are larger on announcement days and that they are increasing with the time to maturity. Secondly, the conditional covariances are larger for longer maturity of one bond (ceteris paribus), and they are also greater on announcement days. Finally, the conditional correlations of the bond excess returns are larger on announcement days. Hence, releases of macroeconomic news induces common movements in the bond market which strengthen the correlations.

It is conceivable that the impact of macroeconomic news releases on bond returns depends on the general state of the economy, i.e. whether we are in a recession or an expansion. In principle, this could be investigated using the U.S. business cycle data prepared by the National Bureau of Economic Research (NBER). However, in the 16 years we consider (1983 to 1998) there are only 8 months of recession (from July 1990 to March 1991), providing a total of 16 announcements during recession. Hence, we would incur serious small sample problems if we were to investigate this hypothesis which has deterred us from looking further into this issue. 
Above we have conducted several specification tests which support the estimated model. Yet, we would like to know how well the model actually predicts future variances and covariances. One way to assess this would be to regress predicted values on subsequently realized values. However, for second moments, we cannot observe the realized values. Instead, we would have to use sample moments calculated using one observation. Andersen and Bollerslev (1998) show that daily data in a GARCH framework always result in very low R-squares when conducting the above regression (even when the model is correctly specified). They find that high frequency data resolve this problem because this allows us to calculate daily sample moments using several observations. As we do not have access to high frequency data the issue of predictability is left for future research. 


\section{References}

Alexander, C. and Chibumba, A. (1996), Orthogonal GARCH: An Empirical Validation on Equities, Foreign Exchange and Interest Rates, Working paper, School of Mathematical Sciences, University of Sussex, UK.

Andersen, T. G. and Bollerslev, T. (1998), 'Answering the Skeptics: Yes, Standard Volatility Models do Provide Accurate Forecasts', International Economic Review .

Balduzzi, P., Elton, E. J. and Green, T. C. (1997), Economic News and the Yield Curve: Evidence from the U.S. Treasury Market, Working paper, Stern School of Business, New York University.

Bollerslev, T., Chou, R. Y. and Kroner, K. F. (1992), 'ARCH Modeling in Finance', Journal of Econometrics 52, 5-59.

Christiansen, C. (1999), 'Value at Risk Using the Factor-ARCH Model', Journal of Risk Forthcoming.

Davidson, R. and MacKinnon, J. (1993), Estimation and Inference in Econometrics, Oxford University Press.

Diebold, R. and Nerlove, M. (1989), 'The Dynamics of Exchange Rate Volatility: A Multivariate Latent Factor ARCH Model', Journal of Applied Econometrics 4, 121.

Ederington, L. H. and Lee, J. H. (1993), 'How Markets Process Information News Releases and Volatility', Journal of Finance 48(4), 1161-1191.

Engle, R., Ng, V. K. and Rothschild, M. (1990), 'Asset Pricing with a Factor-ARCH Covariance Structure', Journal of Econometrics 45, 213-237.

Fleming, M. J. and Remolona, E. M. (1997), 'What Moves the Bond Market?', Economic Policy Review - Federal Reserve Bank of New York 3(4), 31-50.

Fleming, M. J. and Remolona, E. M. (1999a), 'Price Formation and Liquidity in the U.S. Treasury Market: The Response to Public Information', Journal of Finance 54(5). 
Fleming, M. J. and Remolona, E. M. (1999b), The Term Structure of Announcement Effects, Staff report, Federal Reserve Bank of New York.

Glosten, L., Jagannathan, R. and Runkle, D. (1993), 'On the Relation Between the Expected Value and the Volatility of the Nominal Excess Return on Stocks', Journal of Finance 48, 1779-1801.

Greene, W. H. (1997), Econometric Analysis, 3 edn, Macmillan.

Hamilton, J. D. (1994), Time Series Analysis, Princeton University Press.

Johnson, R. A. and Wichern, D. W. (1992), Applied Multivariate Statistical Analysis, 3 edn, Prentice Hall.

Jones, C. M., Lamont, O. and Lumsdaine, R. L. (1998), 'Macroeconomic News and Bond Market Volatility', Journal of Financial Economics 47, 315-337.

Kroner, K. F. and Ng, V. K. (1998), 'Modeling Asymmetric Comovements of Asset Returns', Review of Financial Studies 11(4), 817-844.

Li, L. and Engle, R. F. (1998), Macroeconomic Announcements and Volatility of Treasury Futures, Discussion Paper 98-27, Dept. of Economics, University of California, San Diego.

Lin, W.-L. (1992), 'Alternative Estimaters for Factor GARCH Models - A Monte Carlo Comparison', Journal of Applied Econometrics 7, 259-279.

Ross, S. (1976), 'The Arbitrage Theory of Capital Asset Pricing', Journal of Economic Theory December, 343-362. 
Panel A: Daily excess returns (in \%) of the 3 year bond:

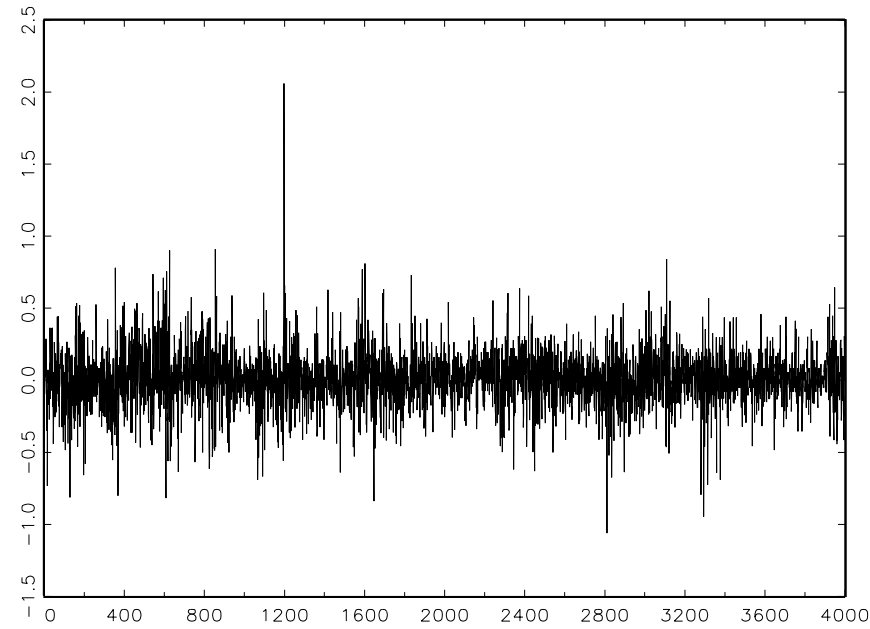

Panel B: Daily excess returns (in \%) of the 10 year bond:

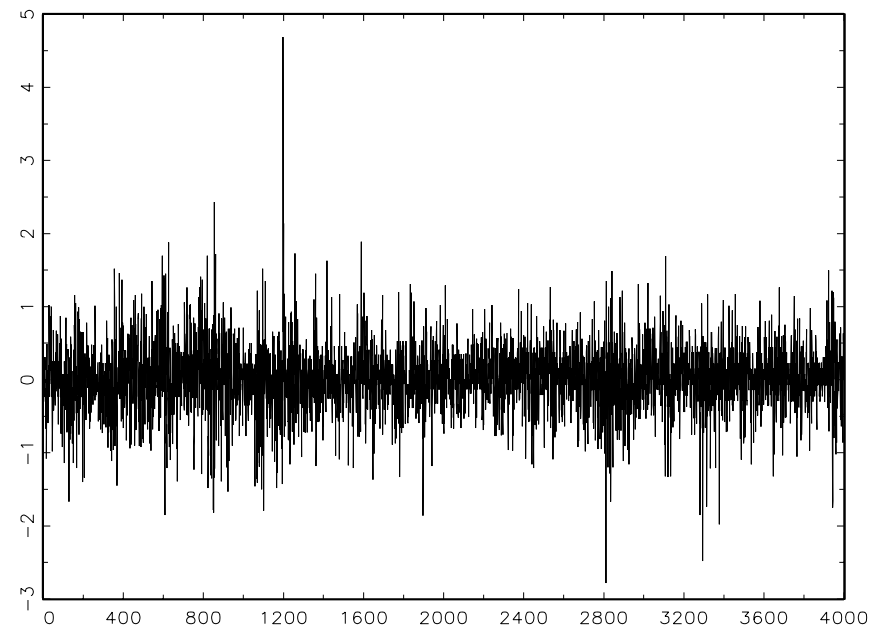

The unit of measurement on the x-axes is trading days elapsed since January 1, 1983.

Figure 1: Daily excess Returns of 3 and 10 Year Bond 
Panel A: Full sample (3999 observations):

\begin{tabular}{l|cccc} 
Maturity & Mean & Std. Dev. & Minimum & Maximum \\
\hline $2 \mathrm{yr}$ & 0.007 & 0.128 & -0.655 & 1.527 \\
$3 \mathrm{yr}$ & 0.009 & 0.188 & -1.060 & 2.058 \\
$5 \mathrm{yr}$ & 0.012 & 0.290 & -1.730 & 3.010 \\
$7 \mathrm{yr}$ & 0.016 & 0.373 & -2.260 & 3.914 \\
$10 \mathrm{yr}$ & 0.018 & 0.459 & -2.780 & 4.690 \\
$30 \mathrm{yr}$ & 0.025 & 0.674 & -3.890 & 7.250
\end{tabular}

\begin{tabular}{l|cccccc}
$\begin{array}{l}\text { Covariance } \\
\text { Correlation }\end{array}$ & $2 \mathrm{yr}$ & $3 \mathrm{yr}$ & $5 \mathrm{yr}$ & $7 \mathrm{yr}$ & $10 \mathrm{yr}$ & $30 \mathrm{yr}$ \\
\hline $2 \mathrm{yr}$ & 0.016 & 0.023 & 0.034 & 0.042 & 0.051 & 0.068 \\
$3 \mathrm{yr}$ & 0.947 & 0.035 & 0.052 & 0.065 & 0.078 & 0.106 \\
$5 \mathrm{yr}$ & 0.922 & 0.954 & 0.084 & 0.104 & 0.126 & 0.173 \\
$7 \mathrm{yr}$ & 0.884 & 0.924 & 0.958 & 0.139 & 0.167 & 0.233 \\
$10 \mathrm{yr}$ & 0.860 & 0.904 & 0.946 & 0.974 & 0.211 & 0.292 \\
$30 \mathrm{yr}$ & 0.786 & 0.835 & 0.884 & 0.926 & 0.945 & 0.455
\end{tabular}

Panel B: Announcement days (376 observations):

\begin{tabular}{|c|c|c|c|c|c|c|}
\hline Maturity & Mean & \multicolumn{2}{|c|}{ Std. Dev. } & Minimum & \multicolumn{2}{|c|}{ Maximum } \\
\hline $2 \mathrm{yr}$ & 0.021 & \multicolumn{2}{|c|}{0.198} & -0.655 & \multicolumn{2}{|c|}{0.585} \\
\hline $3 \mathrm{yr}$ & 0.029 & \multicolumn{2}{|c|}{0.289} & -0.949 & \multicolumn{2}{|c|}{0.910} \\
\hline $5 \mathrm{yr}$ & 0.046 & \multicolumn{2}{|c|}{0.435} & -1.446 & \multicolumn{2}{|c|}{1.310} \\
\hline $7 \mathrm{yr}$ & 0.045 & \multicolumn{2}{|c|}{0.535} & -1.788 & \multicolumn{2}{|c|}{1.869} \\
\hline $10 \mathrm{yr}$ & 0.057 & \multicolumn{2}{|c|}{0.652} & -2.479 & \multicolumn{2}{|c|}{2.430} \\
\hline $30 \mathrm{yr}$ & 0.091 & \multicolumn{2}{|c|}{0.926} & -3.082 & \multicolumn{2}{|c|}{3.040} \\
\hline $\begin{array}{l}\text { Covariance } \\
\text { Correlation }\end{array}$ & $2 \mathrm{yr}$ & $3 \mathrm{yr}$ & $5 \mathrm{yr}$ & $7 \mathrm{yr}$ & $10 \mathrm{yr}$ & $30 \mathrm{yr}$ \\
\hline $2 \mathrm{yr}$ & 0.039 & 0.056 & 0.083 & 0.099 & 0.117 & 0.155 \\
\hline $3 \mathrm{yr}$ & 0.980 & 0.083 & 0.123 & 0.148 & 0.177 & 0.236 \\
\hline $5 \mathrm{yr}$ & 0.961 & 0.978 & 0.189 & 0.228 & 0.275 & 0.370 \\
\hline $7 \mathrm{yr}$ & 0.935 & 0.957 & 0.982 & 0.287 & 0.345 & 0.470 \\
\hline $10 \mathrm{yr}$ & 0.910 & 0.940 & $0.9 \% 0$ & 0.988 & 0.426 & 0.581 \\
\hline $30 \mathrm{yr}$ & 0.849 & 0.884 & 0.919 & 0.949 & 0.961 & 0.857 \\
\hline
\end{tabular}


Panel C: Non-announcement days (3623 observations):

\begin{tabular}{|c|c|c|c|c|c|c|}
\hline Maturity & Mean & \multicolumn{2}{|c|}{ Std. Dev. } & Minimum & \multicolumn{2}{|c|}{ Maximum } \\
\hline $2 \mathrm{yr}$ & 0.006 & 0.118 & & -0.655 & $1.5^{\circ}$ & \\
\hline $3 \mathrm{yr}$ & 0.007 & 0.17 & & -1.060 & 2.0 & \\
\hline $5 \mathrm{yr}$ & 0.009 & 0.27 & & -1.730 & 3.01 & \\
\hline $7 \mathrm{yr}$ & 0.013 & 0.35 & & -2.260 & 3.91 & \\
\hline $10 \mathrm{yr}$ & 0.014 & 0.43 & & -2.780 & 4.69 & \\
\hline $30 \mathrm{yr}$ & 0.018 & 0.64 & & -3.890 & 7.2 & \\
\hline $\begin{array}{l}\text { Covariance } \\
\text { Correlation }\end{array}$ & $2 \mathrm{yr}$ & $3 \mathrm{yr}$ & $5 \mathrm{yr}$ & $7 \mathrm{yr}$ & $10 \mathrm{yr}$ & $30 \mathrm{yr}$ \\
\hline $2 \mathrm{yr}$ & 0.014 & 0.019 & 0.029 & 0.036 & 0.044 & 0.059 \\
\hline $3 \mathrm{yr}$ & 0.937 & 0.030 & 0.045 & 0.056 & 0.068 & 0.092 \\
\hline $5 \mathrm{yr}$ & 0.911 & $0.94^{7}$ & 0.073 & 0.090 & 0.110 & 0.152 \\
\hline $7 \mathrm{yr}$ & 0.871 & 0.916 & 0.952 & 0.124 & 0.148 & 0.208 \\
\hline $10 \mathrm{yr}$ & 0.848 & 0.896 & 0.940 & $0.9^{r} 71$ & 0.188 & 0.262 \\
\hline $30 \mathrm{yr}$ & 0.772 & 0.824 & $0.8^{m 7}$ & 0.921 & 0.941 & 0.413 \\
\hline
\end{tabular}

Summary statistics for treasury bond excess returns (in \%, i.e. scaled by 100) for the period January 1, 1983 to December 31, 1998. Announcement days denote days in the sample period when the Bureau of Labor Statistics published Employment Situation reports or PPI statistics. Numbers in italic are the correlation coefficients.

Table 1: Summary Statistics: Treasury Bond Excess Returns 


\begin{tabular}{l|cccccc}
$i$ (maturity) & $2 \mathrm{yr}$ & $3 \mathrm{yr}$ & $5 \mathrm{yr}$ & $7 \mathrm{yr}$ & $10 \mathrm{yr}$ & $30 \mathrm{yr}$ \\
\hline$R_{i t}$ & 0.015 & 0.022 & 0.037 & 0.032 & 0.044 & 0.074 \\
& $(0.010)$ & $(0.015)$ & $(0.023)$ & $(0.028)$ & $(0.034)$ & $(0.049)$ \\
$R_{2 \mathrm{yr} t} R_{i t}$ & $0.025^{* * *}$ & $0.037^{* * *}$ & $0.054^{* * *}$ & $0.063^{* * *}$ & $0.075^{* * *}$ & $0.098^{* * *}$ \\
& $(0.004)$ & $(0.005)$ & $(0.008)$ & $(0.009)$ & $(0.011)$ & $(0.015)$ \\
$R_{3 \mathrm{yr} R_{i t}}$ & & $0.054^{* * *}$ & $0.079^{* * *}$ & $0.093^{* * *}$ & $0.111^{* * *}$ & $0.146^{* * *}$ \\
& & $(0.008)$ & $(0.011)$ & $(0.014)$ & $(0.017)$ & $(0.022)$ \\
$R_{5 \mathrm{yr} t} R_{i t}$ & & & $0.118^{* * *}$ & $0.139^{* * *}$ & $0.167^{* * *}$ & $0.221^{* * *}$ \\
& & & $(0.017)$ & $(0.0221)$ & $(0.025)$ & $(0.034)$ \\
$R_{7 \mathrm{yr} t} R_{i t}$ & & & & $0.164^{* * *}$ & $0.198^{* * *}$ & $0.265^{* * *}$ \\
& & & & $(0.026)$ & $(0.032)$ & $(0.046)$ \\
$R_{10 \mathrm{yr} t} R_{i t}$ & & & & & $0.239^{* * *}$ & $0.322^{* * *}$ \\
& & & & & $(0.040)$ & $(0.053)$ \\
$R_{30 \mathrm{yr} t} R_{i t}$ & & & & & & $0.450^{* * *}$ \\
& & & & & & $(0.074)$
\end{tabular}

Coefficients of univariate OLS regressions of $R_{i t}$ and $R_{i t} R_{j t}$ respectively on $I_{t}^{A}$, where $R_{i t}$ is the excess return for bond $i$ and $I_{t}^{A}$ is an indicator function for announcement days, (intercept coefficients not reported). White's standard errors in parenthesis. ${ }^{*}(* *)[* * *]$ indicates that the parameter is significantly different from zero at a 10\% (5\%) [1\%] level.

Table 2: OLS Regressions 


\begin{tabular}{l|cccccc} 
Maturity & $2 \mathrm{yr}$ & $3 \mathrm{yr}$ & $5 \mathrm{yr}$ & $7 \mathrm{yr}$ & $10 \mathrm{yr}$ & $30 \mathrm{yr}$ \\
\hline$\Phi_{0 i}$ & $0.005^{* * *}$ & $0.006^{* *}$ & 0.006 & $0.010^{*}$ & 0.011 & 0.015 \\
& $(0.002)$ & $(0.003)$ & $(0.004)$ & $(0.006)$ & $(0.007)$ & $(0.011)$ \\
$\Phi_{1,2 \mathrm{yr}}$ & 0.027 & $0.416^{* * *}$ & $0.490^{* * *}$ & $0.476^{* *}$ & $0.427^{*}$ & $0.766^{* *}$ \\
& $(0.071)$ & $(0.102)$ & $(0.154)$ & $(0.202)$ & $(0.250)$ & $(0.365)$ \\
$\Phi_{1,3 \mathrm{yr}}$ & 0.060 & $-0.247^{* * *}$ & -0.035 & -0.130 & -0.085 & -0.359 \\
& $(0.048)$ & $(0.070)$ & $(0.108)$ & $(0.140)$ & $(0.175)$ & $(0.247)$ \\
$\Phi_{1,5 \mathrm{yr}}$ & 0.004 & 0.010 & $-0.235^{* * *}$ & 0.049 & -0.025 & -0.241 \\
& $(0.037)$ & $(0.053)$ & $(0.083)$ & $(0.110)$ & $(0.137)$ & $(0.202)$ \\
$\Phi_{1,7 \mathrm{yr}}$ & 0.035 & $0.078^{*}$ & $0.171^{* * *}$ & -0.054 & $0.213^{*}$ & 0.036 \\
& $(0.029)$ & $(0.043)$ & $(0.067)$ & $(0.091)$ & $(0.113)$ & $(0.172)$ \\
$\Phi_{1,10 \mathrm{yr}}$ & -0.027 & -0.014 & -0.010 & 0.035 & $-0.164^{*}$ & $0.300^{* *}$ \\
& $(0.025)$ & $(0.037)$ & $(0.056)$ & $(0.075)$ & $(0.093)$ & $(0.145)$ \\
$\Phi_{1,30 \mathrm{yr}}$ & -0.007 & 0.016 & -0.022 & -0.011 & 0.014 & $-0.101^{*}$ \\
& $(0.010)$ & $(0.015)$ & $(0.023)$ & $(0.030)$ & $(0.037)$ & $(0.056)$ \\
$\delta_{1 i}$ & 0.014 & 0.022 & 0.036 & 0.032 & 0.043 & 0.074 \\
& $(0.010)$ & $(0.015)$ & $(0.023)$ & $(0.028)$ & $(0.034)$ & $(0.048)$
\end{tabular}

The VAR-residuals are created as the residuals, $y_{t}$, from estimating the following equation by OLS: $R_{t}=\Phi_{0}+\Phi_{1} R_{t-1}+\delta_{1} I_{t}^{A}+y_{t}$, where $R_{t}$ is the vector of excess returns at time $t$, and $I_{t}^{A}$ is an indicator function for announcement days. White's standard errors in parenthesis. ${ }^{*}\left({ }^{* *}\right)\left[{ }^{* * *}\right]$ indicates that the parameter is significantly different from zero (two-sided test) at a 10\% (5\%) [1\%] level.

Table 3: Conditional Mean Equation 
Panel A: Fraction of variation explained by the PCs:

\begin{tabular}{l|cccccc}
$k$ & 1 & 2 & 3 & 4 & 5 & 6 \\
\hline$\lambda_{k} / \sum \lambda_{k}$ & $92.7 \%$ & $4.7 \%$ & $1.1 \%$ & $0.7 \%$ & $0.5 \%$ & $0.4 \%$
\end{tabular}

$\lambda_{k}$ is the $k$ th largest eigenvalue of $x^{\prime} x$, where $x$ is the matrix of normalized VAR-residuals. The proportion of variation in $x^{\prime} x$ explained by the $k$ th $\mathrm{PC}$ is equal to the corresponding eigenvalue divided by the sum of all the eigenvalues.

Panel B: Weights of the FRPs:

\begin{tabular}{c|cccccc} 
& $2 \mathrm{yr}$ & $3 \mathrm{yr}$ & $5 \mathrm{yr}$ & $7 \mathrm{yr}$ & $10 \mathrm{yr}$ & $30 \mathrm{yr}$ \\
\hline$\hat{\alpha}_{1}$ & 0.397 & 0.409 & 0.417 & 0.417 & 0.414 & 0.395 \\
$\hat{\alpha}_{2}$ & -0.588 & -0.387 & -0.115 & 0.173 & 0.310 & 0.605
\end{tabular}

$\hat{\alpha}_{k}$ is the weight of the $k$ th PC of the normalized VAR-residuals, $x$. Hence, the returns of the $k$ th FRP is given as: $P_{k t} \equiv \hat{\alpha}_{k}^{\prime} x_{t}$.

Table 4: Principal Components Analysis 
Panel A: QML estimates of ordinary GARCH(1,1) model:

\begin{tabular}{c|ccc} 
& $\sigma_{k}$ & $\phi_{k}$ & $\varphi_{k}$ \\
\hline$k=1$ & $0.126^{* * *}$ & $0.043^{* * *}$ & $0.935^{* * *}$ \\
& $(0.039)$ & $(0.011)$ & $(0.014)$ \\
$k=2$ & $0.009^{* *}$ & $0.057^{* * *}$ & $0.912^{* * *}$ \\
& $(0.004)$ & $(0.013)$ & $(0.024)$
\end{tabular}

QML estimates of the ordinary GARCH(1,1) model of the FRP returns, $P_{k t}: P_{k t} \mid F_{t-1} \sim \mathrm{N}\left(0, \theta_{k t}\right)$, where $\theta_{k t}=\sigma_{k}+\phi_{k} P_{k, t-1}^{2}+\varphi_{k} \theta_{k, t-1}$. Robust standard errors in parenthesis. * $\left(^{* *}\right)[* * *]$ indicates that the parameter is significantly different from zero at a $10 \%$ (5\%) [1\%] level.

Panel B: QML estimates of simple GARCH(1,1) model:

\begin{tabular}{c|cccc} 
& $\delta_{k 2}$ & $\sigma_{k}$ & $\phi_{k}$ & $\varphi_{k}$ \\
\hline$k=1$ & $1.779^{* * *}$ & $0.116^{* * *}$ & $0.054^{* * *}$ & $0.923^{* * *}$ \\
& $(0.228)$ & $(0.031)$ & $(0.027)$ & $(0.014)$ \\
$k=2$ & $0.672^{* * *}$ & $0.010^{* * *}$ & $0.062^{* * *}$ & $0.890^{* * *}$ \\
& $(0.150)$ & $(0.004)$ & $(0.015)$ & $(0.028)$
\end{tabular}

QML estimates of the simple GARCH(1,1) model of the FRP returns, $P_{k t}: P_{k t}=\left(1+\delta_{k 2} I_{t}^{A}\right)^{\cdot 5} \epsilon_{k t}$, where $\epsilon_{k t} \mid F_{t-1} \sim \mathrm{N}\left(0, \theta_{k t}\right), \theta_{k t}=\sigma_{k}+\phi_{k} \epsilon_{k, t-1}^{2}+\varphi_{k} \theta_{k, t-1}$, and $I_{t}^{A}$ is an indicator function for announcement days. Robust standard errors in parenthesis. ${ }^{*}(* *)\left[{ }^{* *}\right]$ indicates that the parameter is significantly different from zero at a $10 \%(5 \%)[1 \%]$ level.

Table 5: Ordinary and Simple GARCH(1,1) Models of Daily FRP Returns 
Panel A: QML estimates:

\begin{tabular}{l|ccccccc} 
Parameter: & $\delta_{2 k}$ & $\sigma_{k}$ & $\phi_{k}$ & $\delta_{3 k}$ & $\delta_{4 k}$ & $\varphi_{k}$ & $\delta_{5 k}$ \\
\hline$k=1$ & $1.680^{* * *}$ & $0.120^{* * *}$ & $0.056^{* * *}$ & $-0.056^{* * *}$ & 0.024 & $0.921^{* * *}$ & 0.028 \\
& $(0.255)$ & $(0.030)$ & $(0.013)$ & $(0.013)$ & $(0.028)$ & $(0.018)$ & $(0.091)$ \\
$k=2$ & $0.880^{* * *}$ & $0.011^{* *}$ & $0.059^{* * *}$ & 0.040 & 0.027 & $0.880^{* * *}$ & $0.158^{* *}$ \\
& $(0.176)$ & $(0.005)$ & $(0.014)$ & $(0.058)$ & $(0.061)$ & $(0.029)$ & $(0.079)$
\end{tabular}

QML estimates of the general GARCH(1,1) model of the FRP returns, $P_{k t}: P_{k t}=\left(1+\delta_{k 2} I_{t}^{A}\right)^{.5} \epsilon_{k t}$, where $\epsilon_{k t} \mid F_{t-1} \sim \mathrm{N}\left(0, \theta_{k t}\right), \theta_{k t}=\sigma_{k}+\left(\phi_{k}+\delta_{3 k} I_{t-1}^{A}+\delta_{4 k} I_{t-1}^{A} I_{k, t-1}^{-}\right) \epsilon_{k, t-1}^{2}+\left(\varphi_{k}+\delta_{5 k} I_{t-1}^{A}\right) \theta_{k, t-1}$, $I_{t}^{A}$ is an indicator function for announcement days, and $I_{k t}^{-}=1$ for $P_{k t}<0$ and 0 else. Robust standard errors in parenthesis. ${ }^{*}(* *)\left[{ }^{* * *}\right]$ indicates that the parameter is significantly different from zero at a $10 \%(5 \%)$ [1\%] level.

Panel B: Diagnostic tests:

\begin{tabular}{l|ll} 
& $k=1$ & $k=2$ \\
\hline Mean & -0.001 & -0.000 \\
Std. Dev. & 1.000 & 1.001 \\
Skewness & -0.017 & $-0.202^{* * *}$ \\
Excess Kurtosis & $2.532^{* * *}$ & $1.348^{* * *}$ \\
ARCH(2) & 1.614 & 0.682 \\
Autocorr.(5) & 4.140 & 7.962
\end{tabular}

Various test statistics concerning the studentized residuals of the model estimated in Panel A. The test statistic for skewness is calculated as in Davidson and MacKinnon (1993, p. 568). The test statistic for excess kurtosis is calculated as in Davidson and MacKinnon (1993, p. 569). The test for ARCH(2) is a LM test, cf. Hamilton (1994, p. 664). The test for autocorrelation is the Ljung-Box test, cf. Greene (1997, p. 595). * (**) [***] indicates that the test statistic is significant at a $10 \%(5 \%)[1 \%]$ level.

Table 6: General GARCH(1,1) Model of Daily FRP Returns 
Panel A: QML estimates:

\begin{tabular}{l|cccc} 
Parameter: & $\delta_{2 k}$ & $\sigma_{k}$ & $\phi_{k}$ & $\varphi_{k}$ \\
\hline$k=1$ & $1.641^{* * *}$ & $0.120^{* * *}$ & $0.056^{* * *}$ & $0.925^{* * *}$ \\
& $(0.235)$ & $(0.029)$ & $(0.013)$ & $(0.013)$ \\
$k=2$ & $0.705^{* * *}$ & $0.008^{* *}$ & $0.052^{* * *}$ & $0.923^{* * *}$ \\
& $(0.155)$ & $(0.003)$ & $(0.012)$ & $(0.019)$
\end{tabular}

QML estimates of the reduced GARCH(1,1) model of the FRP returns, $P_{k t}: \$ P_{k t}=\left(1+\delta_{k 2} I_{t}^{A}\right)^{.5} \epsilon_{k t}$, where $\epsilon_{k t} \mid F_{t-1} \sim \mathrm{N}\left(0, \theta_{k t}\right), \theta_{k t}=\sigma_{k}+\phi_{k}\left(1-I_{t-1}^{A}\right) \epsilon_{k, t-1}^{2}+\varphi_{k} \theta_{k, t-1}$, and $I_{t}^{A}$ is an indicator function for announcement days. Robust standard errors in parenthesis. ${ }^{*}(* *)[* * *]$ indicates that the parameter is significantly different from zero at a $10 \%(5 \%)[1 \%]$ level.

Panel B: Diagnostic tests:

\begin{tabular}{l|ll} 
& $k=1$ & $k=2$ \\
\hline Mean & -0.001 & 0.000 \\
Std. Dev. & 1.000 & 1.001 \\
Skewness & -0.010 & $-0.201^{* * *}$ \\
Excess Kurtosis & $2.529^{* * *}$ & $1.491^{* * *}$ \\
ARCH(2) & 1.531 & $5.683^{*}$ \\
Autocorr.(5) & 4.140 & 7.962
\end{tabular}

Various test statistics concerning the studentized residuals of the model estimated in Panel A. The test statistic for skewness is calculated as in Davidson and MacKinnon (1993, p. 568). The test statistic for excess kurtosis is calculated as in Davidson and MacKinnon (1993, p. 569). The test for ARCH(2) is a LM test, cf. Hamilton (1994, p. 664). The test for autocorrelation is the Ljung-Box test, cf. Greene $\left(1997\right.$, p. 595). ${ }^{*}(* *)[* *]$ indicates that the test statistic is significantly different from the hypothesis at a $10 \%(5 \%)[1 \%]$ level.

Table 7: Reduced GARCH(1,1) Model of Daily FRP Returns 
Panel A: QML estimates:

\begin{tabular}{c|cccccc} 
& $2 \mathrm{yr}$ & $3 \mathrm{yr}$ & $5 \mathrm{yr}$ & $7 \mathrm{yr}$ & $10 \mathrm{yr}$ & $30 \mathrm{yr}$ \\
\hline$\Omega$ & 0.001 & 0.001 & $0.003^{* * *}$ & $0.004^{* * *}$ & $0.003^{* * *}$ & $0.038^{* * *}$ \\
& $(-)$ & $(-)$ & $(0.000)$ & $(0.000)$ & $(0.000)$ & $(0.002)$ \\
$\beta_{1}$ & $0.051^{* * *}$ & $0.078^{* * *}$ & $0.120^{* * *}$ & $0.155^{* * *}$ & $0.189^{* * *}$ & $0.260^{* * *}$ \\
& $(0.002)$ & $(0.002)$ & $(0.002)$ & $(0.005)$ & $(0.009)$ & $(0.016)$ \\
$\beta_{2}$ & 0.046 & 0.043 & -0.015 & -0.125 & $-0.225^{*}$ & $-0.424^{* *}$ \\
& $(0.033)$ & $(0.050)$ & $(0.078)$ & $0.100)$ & $(0.122)$ & $(0.170)$
\end{tabular}

QML estimates of the covariance matrix of the VAR-residuals, $y_{t}: y_{t} \mid F_{t-1} \sim \mathrm{N}\left(0, H_{t}\right)$, where $H_{t}=\Omega+\beta_{1} \beta_{1}^{\prime}\left(\left(1+\delta_{21} I_{t}^{A}\right) \theta_{1 t}-\sigma_{1}\right)+\beta_{2} \beta_{2}^{\prime}\left(\left(1+\delta_{22} I_{t}^{A}\right) \theta_{2 t}-\sigma_{2}\right), I_{t}^{A}$ is an indicator function for announcement days, and $\left(1+\delta_{2 k} I_{t}^{A}\right) \theta_{k t}$ is the conditional variance of the $k$ th FRP. The estimation is conducted applying the restriction that $\Omega$ be positive definite. Robust standard errors in parenthesis. $^{*}(* *)[* * *]$ indicates that the parameter is significantly different from zero at a $10 \%(5 \%)[1 \%]$ level.

Panel B: Diagnostic tests:

\begin{tabular}{l|llllll} 
& $2 \mathrm{yr}$ & $3 \mathrm{yr}$ & $5 \mathrm{yr}$ & $7 \mathrm{yr}$ & $10 \mathrm{yr}$ & $30 \mathrm{yr}$ \\
\hline Mean & -0.001 & -0.001 & -0.001 & -0.001 & -0.001 & -0.002 \\
Std. Dev. & 0.995 & 0.998 & 0.999 & 0.996 & 0.997 & 1.004 \\
Skewness & $-0.110^{* * *}$ & -0.019 & 0.004 & -0.062 & $-0.095^{* *}$ & -0.044 \\
Excess Kurtosis & $3.255^{* * *}$ & $2.506^{* * *}$ & $2.172^{* * *}$ & $2.223^{* * *}$ & $2.160^{* * *}$ & $2.303^{* * *}$ \\
ARCH(2) & $8.576^{* *}$ & 0.916 & 0.215 & 1.029 & 2.521 & 3.710 \\
Autocorr.(5) & 2.030 & 2.451 & 4.460 & 7.332 & 5.817 & 4.381
\end{tabular}

Various test statistics concerning the studentized residuals of the model estimated in Panel A. The test statistic for skewness is calculated as in Davidson and MacKinnon (1993, p. 568). The test statistic for excess kurtosis is calculated as in Davidson and MacKinnon (1993, p. 569). The test for ARCH(2) is a LM test, cf. Hamilton (1994, p. 664). The test for autocorrelation is the Ljung-Box test, cf. Greene (1997, p. 595).* $\left.{ }^{* *}\right)[* * *]$ indicates that the test statistic is significantly different from the hypothesis at a $10 \%(5 \%)[1 \%]$ level.

Table 8: Two Factor Model of Daily VAR-Residuals 
Panel A: QML estimates:

\begin{tabular}{c|cccccc} 
& $2 \mathrm{yr}$ & $3 \mathrm{yr}$ & $5 \mathrm{yr}$ & $7 \mathrm{yr}$ & $10 \mathrm{yr}$ & $30 \mathrm{yr}$ \\
\hline$\Omega$ & $0.003^{* * *}$ & $0.004^{* * *}$ & $0.004^{* * *}$ & $0.003^{* * *}$ & $0.008^{* * *}$ & $0.059^{* * *}$ \\
& $(0.000)$ & $(0.000)$ & $(0.000)$ & $(0.000)$ & $(0.000)$ & $(0.002)$ \\
$\beta_{1}$ & $0.049^{* * *}$ & $0.075^{* * *}$ & $0.120^{* * *}$ & $0.157^{* * *}$ & $0.192^{* * *}$ & $0.269^{* * *}$ \\
& $(0.001)$ & $(0.001)$ & $(0.002)$ & $(0.003)$ & $(0.003)$ & $(0.005)$
\end{tabular}

QML estimates of the covariance matrix of the VAR-residuals, $y_{t}: y_{t} \mid F_{t-1} \sim \mathrm{N}\left(0, H_{t}\right)$, where $H_{t}=\Omega+\beta_{1} \beta_{1}^{\prime}\left(\left(1+\delta_{21} I_{t}^{A}\right) \theta_{1 t}-\sigma_{1}\right), I_{t}^{A}$ is an indicator function for announcement days, and $\left(1+\delta_{21} I_{t}^{A}\right) \theta_{1 t}$ is the conditional variance of the first FRP. The estimation is conducted applying the restriction that $\Omega$ be positive definite. Robust standard errors in parenthesis. $\left.\left.{ }^{*}{ }^{* *}\right){ }^{[* * *}\right]$ indicates that the parameter is significantly different from zero at a $10 \%(5 \%)[1 \%]$ level.

Panel B: Diagnostic tests:

\begin{tabular}{l|llllll} 
& $2 \mathrm{yr}$ & $3 \mathrm{yr}$ & $5 \mathrm{yr}$ & $7 \mathrm{yr}$ & $10 \mathrm{yr}$ & $30 \mathrm{yr}$ \\
\hline Mean & -0.001 & -0.001 & -0.001 & -0.001 & -0.001 & -0.001 \\
Std. Dev. & 0.980 & 0.985 & 0.995 & 0.999 & 1.002 & 1.009 \\
Skewness & $0.139^{* * *}$ & -0.011 & 0.005 & -0.056 & $-0.080^{* *}$ & -0.014 \\
Excess Kurtosis & $3.638^{* * *}$ & $2.649^{* * *}$ & $2.187^{* * *}$ & $2.275^{* * *}$ & $2.287^{* * *}$ & $2.559^{* * *}$ \\
ARCH(2) & $10.542^{* * *}$ & 1.086 & 0.238 & 1.059 & 2.457 & 3.346 \\
Autocorr.(5) & 1.936 & 2.329 & 4.448 & 7.484 & 6.039 & 4.641
\end{tabular}

Various test statistics concerning the studentized residuals of the model estimated in Panel A. The test statistic for skewness is calculated as in Davidson and MacKinnon (1993, p. 568). The test statistic for excess kurtosis is calculated as in Davidson and MacKinnon (1993, p. 569). The test for ARCH(2) is a LM test, cf. Hamilton (1994, p. 664). The test for autocorrelation is the Ljung-Box test, cf. Greene (1997, p. 595).* $\left.{ }^{* *}\right)[* * *]$ indicates that the test statistic is significantly different from the hypothesis at a $10 \%(5 \%)[1 \%]$ level.

Table 9: One Factor Model of Daily VAR-Residuals 
Panel A: Full sample (3998 observations):

\begin{tabular}{|c|c|c|c|c|c|c|}
\hline $\begin{array}{l}\text { Covariance } \\
\text { Correlation }\end{array}$ & $2 \mathrm{yr}$ & $3 \mathrm{yr}$ & $5 \mathrm{yr}$ & $7 \mathrm{yr}$ & $10 \mathrm{yr}$ & $30 \mathrm{yr}$ \\
\hline \multirow[t]{4}{*}{$2 \mathrm{yr}$} & 0.016 & 0.021 & 0.033 & 0.043 & 0.053 & 0.074 \\
\hline & $(0.010)$ & $(0.015)$ & $(0.024)$ & $(0.031)$ & $(0.038)$ & $(0.053)$ \\
\hline & {$[0.008]$} & {$[0.007]$} & {$[0.012]$} & {$[0.015]$} & {$[0.019]$} & {$[0.026]$} \\
\hline & $\{0.164\}$ & $\{0.246\}$ & $\{0.392\}$ & $\{0.514\}$ & $\{0.628\}$ & $\{0.878\}$ \\
\hline \multirow[t]{4}{*}{$3 \mathrm{yr}$} & 0.828 & 0.035 & 0.050 & 0.066 & 0.080 & 0.112 \\
\hline & $(0.059)$ & $(0.023)$ & $(0.036)$ & $(0.048)$ & $(0.058)$ & $(0.082)$ \\
\hline & [0.682] & {$[0.015]$} & {$[0.018]$} & {$[0.023]$} & {$[0.028]$} & {$[0.040]$} \\
\hline & $\{0.986\}$ & $\{0.379\}$ & $\{0.597\}$ & $\{0.784\}$ & $\{0.957\}$ & $\{1.339\}$ \\
\hline \multirow[t]{4}{*}{$5 \mathrm{yr}$} & 0.860 & 0.902 & 0.084 & 0.105 & 0.128 & 0.179 \\
\hline & $(0.049)$ & (0.036) & $(0.058)$ & $(0.076)$ & $(0.093)$ & $(0.130)$ \\
\hline & [0.737] & {$[0.806]$} & {$[0.032]$} & {$[0.037]$} & {$[0.045]$} & {$[0.063]$} \\
\hline & $\{0.989\}$ & $\{0.993\}$ & $\{0.995\}$ & $\{1.248\}$ & $\{1.524\}$ & $\{2.132\}$ \\
\hline \multirow[t]{4}{*}{$7 \mathrm{yr}$} & 0.876 & 0.918 & 0.954 & 0.141 & 0.168 & 0.234 \\
\hline & $(0.043)$ & $(0.030)$ & $(0.017)$ & $(0.100)$ & $(0.122)$ & $(0.170)$ \\
\hline & {$[0.765]$} & {$[0.837]$} & [0.905] & {$[0.052]$} & {$[0.060]$} & {$[0.083]$} \\
\hline & $\{0.990\}$ & $\{0.994\}$ & $\left\{0.99^{7}\right\}$ & $\{1.641\}$ & $\{2.001\}$ & $\{2.798\}$ \\
\hline \multirow[t]{4}{*}{$10 \mathrm{yr}$} & 0.867 & 0.910 & 0.945 & 0.962 & 0.213 & 0.287 \\
\hline & $(0.046)$ & (0.033) & (0.021) & $(0.015)$ & $(0.149)$ & $(0.208)$ \\
\hline & {$[0.750]$} & {$[0.820]$} & {$[0.886]$} & {$[0.920]$} & {$[0.081]$} & {$[0.102]$} \\
\hline & $\{0.990\}$ & $\{0.993\}$ & $\{0.996\}$ & $\left\{0.99^{7}\right\}$ & $\{2.451\}$ & $\{3.417\}$ \\
\hline \multirow[t]{4}{*}{$30 \mathrm{yr}$} & 0.817 & 0.856 & 0.890 & 0.906 & 0.897 & 0.460 \\
\hline & (0.062) & $(0.051)$ & $(0.040)$ & $(0.034)$ & $(0.037)$ & $(0.291)$ \\
\hline & {$[0.664]$} & [0.726] & [0.784] & {$[0.815]$} & [0.798] & {$[0.201]$} \\
\hline & $\{0.985\}$ & $\{0.989\}$ & $\{0.992\}$ & $\{0.993\}$ & $\{0.992\}$ & $\{4.837\}$ \\
\hline
\end{tabular}


Panel B: Announcement days (376 observations):

\begin{tabular}{|c|c|c|c|c|c|c|}
\hline $\begin{array}{l}\text { Covariance } \\
\text { Correlation }\end{array}$ & $2 \mathrm{yr}$ & $3 \mathrm{yr}$ & $5 \mathrm{yr}$ & $7 \mathrm{yr}$ & $10 \mathrm{yr}$ & $30 \mathrm{yr}$ \\
\hline \multirow[t]{4}{*}{$2 y \mathrm{r}$} & 0.035 & 0.048 & 0.077 & 0.101 & 0.123 & 0.172 \\
\hline & $(0.015)$ & $(0.023)$ & $(0.037)$ & $(0.049)$ & $(0.060)$ & $(0.084)$ \\
\hline & {$[0.017]$} & {$[0.022]$} & {$[0.034]$} & {$[0.045]$} & {$[0.055]$} & {$[0.077]$} \\
\hline & $\{0.164\}$ & $\{0.246\}$ & $\{0.392\}$ & $\{0.514\}$ & $\{0.628\}$ & $\{0.878\}$ \\
\hline \multirow[t]{4}{*}{$3 \mathrm{yr}$} & 0.924 & 0.077 & 0.117 & 0.154 & 0.188 & 0.262 \\
\hline & $(0.024)$ & $(0.036)$ & $(0.057)$ & $(0.075)$ & $(0.091)$ & $(0.127)$ \\
\hline & [0.862] & {$[0.037]$} & {$[0.052]$} & {$[0.068]$} & {$[0.084]$} & {$[0.117]$} \\
\hline & $\{0.986\}$ & $\{0.379\}$ & $\{0.597\}$ & $\{0.784\}$ & $\{0.957\}$ & $\{1.339\}$ \\
\hline \multirow[t]{4}{*}{$5 \mathrm{yr}$} & 0.939 & 0.959 & 0.191 & 0.245 & 0.299 & 0.418 \\
\hline & $(0.019)$ & (0.013) & $(0.091)$ & $(0.119)$ & $(0.145)$ & $(0.203)$ \\
\hline & [0.889] & [0.924] & {$[0.087]$} & {$[0.109]$} & {$[0.133]$} & {$[0.186]$} \\
\hline & $\{0.989\}$ & $\{0.993\}$ & $\{0.995\}$ & $\{1.248\}$ & $\{1.524\}$ & $\{2.132\}$ \\
\hline \multirow[t]{4}{*}{$7 \mathrm{yr}$} & 0.946 & 0.966 & 0.982 & 0.324 & 0.392 & 0.548 \\
\hline & $(0.017)$ & $(0.011)$ & $(0.006)$ & $(0.156)$ & $(0.190)$ & $(0.266)$ \\
\hline & [0.901] & [0.936] & [0.965] & {$[0.146]$} & {$[0.175]$} & {$[0.245]$} \\
\hline & $\{0.990\}$ & $\{0.994\}$ & $\left\{0.99^{n} 7\right\}$ & $\{1.641\}$ & $\{2.001\}$ & $\{2.798\}$ \\
\hline \multirow[t]{4}{*}{$10 \mathrm{yr}$} & 0.942 & 0.962 & 0.978 & 0.985 & 0.487 & 0.670 \\
\hline & $(0.018)$ & $(0.012)$ & $\left(0.00^{\prime} 7\right)$ & $(0.005)$ & $(0.233)$ & $(0.325)$ \\
\hline & [0.894] & [0.930] & [0.958] & [0.9"1] & {$[0.221]$} & {$[0.299]$} \\
\hline & $\{0.990\}$ & $\{0.993\}$ & $\{0.996\}$ & $\left\{0.99^{7}\right\}$ & $\{2.451\}$ & $\{3.417\}$ \\
\hline \multirow[t]{4}{*}{$30 \mathrm{yr}$} & 0.919 & 0.938 & 0.953 & 0.960 & 0.957 & 0.995 \\
\hline & $(0.025)$ & $(0.019)$ & $(0.015)$ & $(0.013)$ & (0.014) & $(0.455)$ \\
\hline & [0.853] & {$[0.886]$} & {$[0.913]$} & [0.926] & [0.919] & {$[0.477]$} \\
\hline & $\{0.985\}$ & $\{0.989\}$ & $\{0.992\}$ & $\{0.993\}$ & $\{0.992\}$ & $\{4.837\}$ \\
\hline
\end{tabular}


Panel C: Non-announcement days (3622 observations):

\begin{tabular}{l|cccccc} 
Covariance & $2 \mathrm{yr}$ & $3 \mathrm{yr}$ & $5 \mathrm{yr}$ & $7 \mathrm{yr}$ & $10 \mathrm{yr}$ & $30 \mathrm{yr}$ \\
Correlation & & & & & & \\
\hline $2 \mathrm{yr}$ & 0.015 & 0.018 & 0.028 & 0.037 & 0.045 & 0.063 \\
& $(0.007)$ & $(0.010)$ & $(0.016)$ & $(0.021)$ & $(0.026)$ & $(0.036)$ \\
& {$[0.008]$} & {$[0.007]$} & {$[0.012]$} & {$[0.015]$} & {$[0.019]$} & {$[0.026]$} \\
$3 \mathrm{yr}$ & $\{0.110\}$ & $\{0.164\}$ & $\{0.261\}$ & $\{0.343\}$ & $\{0.419\}$ & $\{0.585\}$ \\
& 0.818 & 0.031 & 0.043 & 0.057 & 0.069 & 0.097 \\
& $(0.052)$ & $(0.016)$ & $(0.025)$ & $(0.032)$ & $(0.040)$ & $(0.055)$ \\
$5 \mathrm{yr}$ & {$[0.682]$} & {$[0.015]$} & {$[0.018]$} & {$[0.023]$} & {$[0.028]$} & {$[0.040]$} \\
& $\{0.979\}$ & $\{0.254\}$ & $\{0.398\}$ & $\{0.523\}$ & $\{0.638\}$ & $\{0.892\}$ \\
$7 \mathrm{yr}$ & 0.852 & 0.896 & 0.073 & 0.090 & 0.110 & 0.154 \\
& $(0.043)$ & $(0.032)$ & $(0.039)$ & $(0.052)$ & $(0.063)$ & $(0.088)$ \\
& {$[0.737]$} & {$[0.806]$} & {$[0.032]$} & {$[0.037]$} & {$[0.045]$} & {$[0.063]$} \\
& $\{0.984\}$ & $\{0.989\}$ & $\{0.638\}$ & $\{0.832\}$ & $\{1.016\}$ & $\{1.421\}$ \\
$10 \mathrm{yr}$ & 0.869 & 0.913 & 0.952 & 0.121 & 0.145 & 0.202 \\
& $(0.038)$ & $(0.027)$ & $(0.016)$ & $(0.068)$ & $(0.083)$ & $(0.116)$ \\
& {$[0.765]$} & {$[0.837]$} & {$[0.905]$} & {$[0.052]$} & {$[0.060]$} & {$[0.083]$} \\
& $\{0.985\}$ & $\{0.991\}$ & $\{0.995\}$ & $\{1.095\}$ & $\{1.334\}$ & $\{1.865\}$ \\
$30 \mathrm{yr}$ & 0.860 & 0.904 & 0.942 & 0.960 & 0.184 & 0.247 \\
& $(0.041)$ & $(0.030)$ & $(0.019)$ & $(0.013)$ & $(0.101)$ & $(0.141)$ \\
& {$[0.750]$} & {$[0.820]$} & {$[0.886]$} & {$[0.921]$} & {$[0.081]$} & {$[0.102]$} \\
& $\{0.984\}$ & $\{0.990\}$ & $\{0.994\}$ & $\{0.996\}$ & $\{1.637\}$ & $\{2.278\}$ \\
& 0.806 & 0.848 & 0.883 & 0.900 & 0.890 & 0.404 \\
& $(0.055)$ & $(0.045)$ & $(0.036)$ & $(0.030)$ & $(0.033)$ & $(0.198)$ \\
& {$[0.664]$} & {$[0.726]$} & {$[0.784]$} & {$[0.815]$} & {$[0.798]$} & {$[0.201]$} \\
& $\{0.978\}$ & $\{0.983\}$ & $\{0.988\}$ & $\{0.989\}$ & $\{0.988\}$ & $\{3.244\}$ \\
& & & & &
\end{tabular}

Summary statistics for the conditional covariance and correlation matrix, respectively, of Treasury bond excess returns using the 1 factor-ARCH model described in the text. Numbers in italic concern the correlation coefficients. Numbers without brackets are sample means, whereas (-), [-], and $\{-\}$ denote standard deviation, minimum value, and maximum value, respectively.

Table 10: Summary Statistics for the Conditional Covariance and Correlation Matrixes 